\title{
Synergistic effects of multiple enzymes from industrial Aspergillus niger strain 01 on starch saccharification
}

\author{
Wenzhu Guo ${ }^{1,2+}$, Jianhua Yang ${ }^{1,2 \dagger}$, Tianchen Huang ${ }^{1,2}$, Dandan Liu ${ }^{1,2}$, Qian Liu ${ }^{1,2}$, Jingen Li ${ }^{1,2}$, Wenliang Sun ${ }^{1,2}$, \\ Xingji Wang ${ }^{3}$, Leilei Zhu ${ }^{1,2^{*}}$ and Chaoguang Tian ${ }^{1,2^{*}} \mathbb{C}$
}

\begin{abstract}
Background: Starch is one of the most important renewable polysaccharides in nature for production of bio-ethanol. The starch saccharification step facilitates the depolymerization of starch to yield glucose for biofuels production. The filamentous fungus Aspergillus niger (A. niger) is the most used microbial cell factory for production of the commercial glucoamylase. However, the role of each component in glucoamylases cocktail of $A$. niger $\mathrm{O} 1$ for starch saccharification remains unclear except glucoamylase.
\end{abstract}

Results: In this study, we identified the key enzymes contributing to the starch saccharification process are glucoamylase, a-amylase and acid a-amylase out of 29 glycoside hydrolases from the 6-day fermentation products of $A$. niger 01. Through the synergistic study of the multienzymes for the starch saccharification in vitro, we found that increasing the amount of a-amylase by 5-10 times enhanced the efficiency of starch saccharification by $14.2-23.2 \%$. Overexpression of acid a-amylase in strain $\mathrm{O} 1$ in vivo increased the total glucoamylase activity of $\mathrm{O} 1$ cultures by $15.0 \%$.

Conclusions: Our study clarifies the synergistic effects among the components of glucoamylases cocktail, and provides an effective approach to optimize the profile of saccharifying enzymes of strain $\mathrm{O} 1$ for improving the total glucoamylase activity.

Keywords: Aspergillus niger, Glucoamylase, a-Amylase, Starch saccharification, Synergistic effects

\section{Background}

Starch is one of the most important renewable polysaccharides for the production of bio-ethanol $[1,2]$. Starch is composed of two $\alpha$-glucan polymers, amylose and amylopectin [3]. Amylose is a linear chain of $\alpha$-glucose linked by $\alpha-1,4-$ glycosidic linkages, while amylopectin is a branched macromolecule linked by $\alpha-1,4$-glycosidic linkages and $\alpha-1,6$-glycosidic linkages [4-6]. Cost-effective

\footnotetext{
*Correspondence: zhu_II@tib.cas.cn; tian_cg@tib.cas.cn

${ }^{\dagger}$ Wenzhu Guo and Jianhua Yang contributed equally to this work

${ }^{1}$ Key Laboratory of Systems Microbial Biotechnology, Tianjin Institute

of Industrial Biotechnology, Chinese Academy of Sciences, Tianjin 300308, China

Full list of author information is available at the end of the article
}

conversion of raw starch to biofuels requires efficient starch-hydrolyzing enzyme system.

Aspergillus niger (A. niger) strains can secrete a broad range of hydrolytic enzymes required for degradation of polymeric substances (e.g. starch) to release nutrients [7, 8]. The filamentous fungus $A$. niger is used as microbial cell factory for production of lignocellulolytic enzymes and amylolytic enzymes [9-12]. Amylolytic enzymes that hydrolyze the glycosidic linkages in $\alpha$-glucans belong to three glycoside hydrolases (GHs) families: GH13 ( $\alpha$-amylases), GH14 ( $\beta$-amylases) and GH15 (glucoamylases) $[5,13,14] . \alpha$-Amylases and glucoamylases are widely used in starch conversion [15]. $\alpha$-Amylases can randomly cleave the internal $\alpha-1,4$-glycosidic linkages in starch to generate maltose and malto-oligosaccharides original author(s) and the source, provide a link to the Creative Commons licence, and indicate if changes were made. The images or other third party material in this article are included in the article's Creative Commons licence, unless indicated otherwise in a credit line to the material. If material is not included in the article's Creative Commons licence and your intended use is not permitted by statutory regulation or exceeds the permitted use, you will need to obtain permission directly from the copyright holder. To view a copy of this licence, visit http://creativecommons.org/licenses/by/4.0/. The Creative Commons Public Domain Dedication waiver (http://creativeco mmons.org/publicdomain/zero/1.0/) applies to the data made available in this article, unless otherwise stated in a credit line to the data. 
[16-18]. Glucoamylase (glucan 1,4- $\alpha$-glucosidase) is a typical exo-acting enzyme that hydrolyzes starch completely into glucose from the non-reducing ends [12, 19-21]. Starch liquefaction by thermostable $\alpha$-amylase and saccharification mainly by glucoamylase are sequentially carried out to produce glucose from starch for the production of bio-ethanol in industry [22, 23]. Therefore, glucoamylase is one of the most needed industrial enzymes in biofuel industry [24].

Commercial glucoamylase is usually produced by fermentation process of $A$. niger. Commercial glucoamylase used in industrial production is a glucoamylases cocktail (multi-enzyme system). Moreover, it has been reported that improving the expression of some specific enzymes can enhance the total enzyme activity of the glucoamylase enzyme system. Synergistic action of $\alpha$-amylase and glucoamylase on hydrolysis of starch in vitro showed that at the early stage of reaction, $\alpha$-amylase accelerated the rate of formation of glucose by supplying newly formed non-reducing ends of starch molecules [25]. By overexpressing amyA and glaA, An et al. increased the total extracellular glucoamylase activity of $A$. niger by $44.1 \%$ with $1 \%$ casein phosphopeptides added to the fermentation medium [22]. Parahar et al. achieved one-step starch saccharification by engineering a chimeric acid-stable $\alpha$-amylase-glucoamylase in E. coli [26]. Wang et al. provided evidence for synergistic effect of $\alpha$-amylase and glucoamylase on alcoholic fermentation for Chinese baijiu production [27]. The activities of total glucoamylase in red and white koji were similar. The $\alpha$-amylase activity in white koji was 100 -fold higher than that in red koji and saccharification in red koji is lower than that in white koji due to low $\alpha$-amylase activity. They speculated that increasing $\alpha$-amylase production enhance red koji activity in saccharification [28]. However, except for the main glucoamylase, the contribution of each component within the multiple starch degradation enzymes composing glucoamylase cocktails remains unclear. Therefore, it is important to study their synergistic effects on starch saccharification for further improvement of glucoamylase cocktail performance to achieve efficient glucose production.

In this study, we purified and characterized the main components of the enzymes from the fermentation product of an industrial glucoamylase-producing strain $A$. niger $\mathrm{O} 1$. The contribution of each component in the starch saccharification was investigated by combination of synergistic study of glucoamylase system in vitro and genetic manipulation in vivo. Our study clarifies the synergistic effects among the components of glucoamylases cocktail, and provides an effective approach to optimize the total activity of glucoamylases cocktail produced by industrial fungal strain $\mathrm{O} 1$.

\section{Results}

Profile of the secreted proteins of $A$. niger strain 01

The filtered supernatants of 2-day $(2 \mathrm{~d}), 4$-day $(4 \mathrm{~d})$ and 6-day ( $6 \mathrm{~d}$ ) shake-flask cultures of $A$. niger strain $\mathrm{O} 1$ were analyzed by SDS-PAGE (Fig. 1a). To explore the changes of secreted proteins in fermentation process, filtered supernatants were analyzed using liquid chromatography combined with tandem mass spectrometry (LC-MS/MS). Label-free quantitative proteomics approach was used to study the enzyme profile in the fermentation cultures. As a result, 111, 60 and 78 proteins were identified from the 2 days, 4 days and 6 days fermentation supernatants, respectively (Fig. 1b). There were 19, 20 and 29 glycoside hydrolases detected in 2-day, 4-day and 6-day fermentation supernatants and the ratio of glycoside hydrolases in identified proteins are $17.1 \%, 33.3 \%$ and $37.2 \%$ in 2-day, 4-day, 6-day fermentation cultures, respectively (Fig. 1b; Additional file 1: Fig. S1). 24 proteins were consistently present in 2-day, 4-day and 6-day supernatants in fermentation process (Fig. 1c). 13 proteins among these 24 proteins belong to glycoside hydrolase families. Glucoamylase of GH15, $\alpha$-amylase and acid $\alpha$-amylase of GH13 are the most abundant proteins in 2-day, 4-day and 6-day fermentation cultures, accounting for most part of the total proteins (Fig. 1d). Other proteins such as catalase, aspartate aminotransferase, $\alpha$-glucosidase and endoglucanase also take a certain proportion of secretome.

\section{Isolation, purification, and identification of enzymes related to starch saccharification from secreted proteins of $A$. niger strain 01}

The procedure of isolation and identification of enzymes contributing to the starch saccharification from the 6-day supernatants of the $A$. niger strain $\mathrm{O} 1$ is shown in Fig. 2. Through the isolation and purification of the enzymes by anion exchange chromatography, four main enzyme components (O1-1, O1-2, O1-3, and O1-4) were isolated with the ratio of protein concentration of 9.9:10:0.1:80. The protein concentration was monitored according to the absorbance at UV $280 \mathrm{~nm}$ (Fig. 2a). Therefore, the quantity of O1-1, O1-2, O1-3, and O1-4 was deemed to be $9.9 \%, 10 \%, 0.1 \%$, and $80 \%$ of the total protein, respectively. The molecular weight of O1-1, O1-2, O1-3, and O1-4 are about 50, 75, 63, and $100 \mathrm{kDa}$ as shown on SDS-PAGE, respectively (Fig. 2b). Through LC-MS/ MS detection, O1-1 and O1-3 were identified as neutral $\alpha$-amylase (UniProt: A2QL05) and acid $\alpha$-amylase (UniProt: A2QW02), respectively; O1-2 and O1-4 were confirmed to be glucoamylase (UniProt: A2QHE1) (Fig. 2b; Additional file 2). The molecular weight of O1-4 is larger than O1-2, which might be caused by the different glycosylation level. After deglycosylation of O1-2 and O1-4 using PNGase F, the sizes of both proteins reduced, but 
a

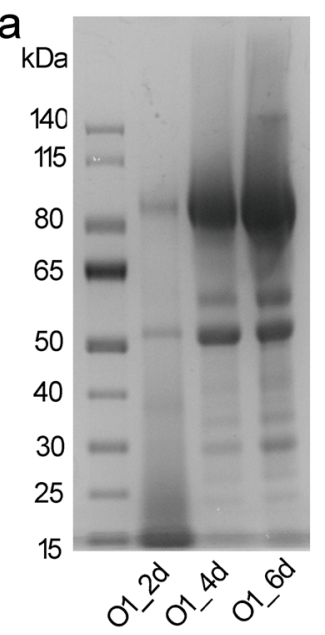

d

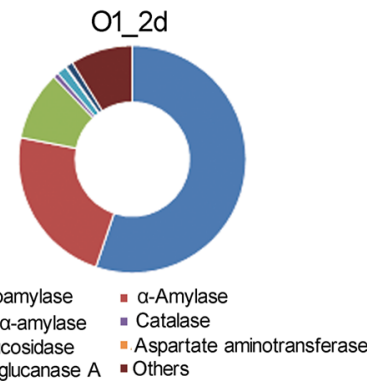

b

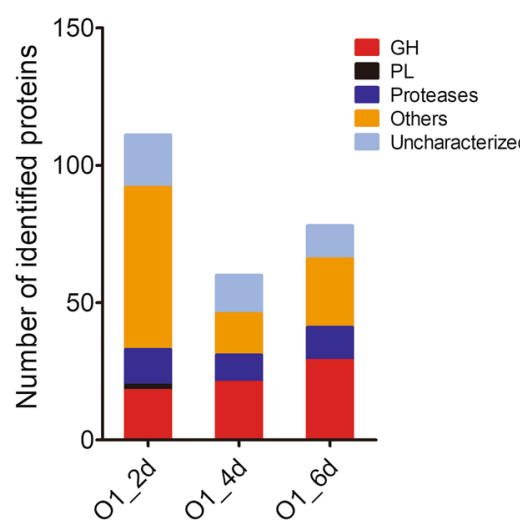

C
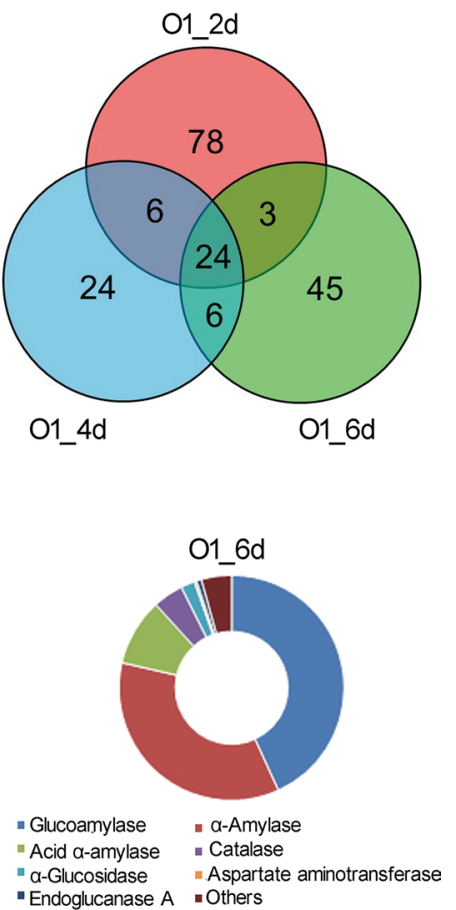

Fig. 1 Comparative secretome analysis of the A. niger $\mathrm{O} 1$ in shake-flask fermentation. a SDS-PAGE analysis of secreted proteins in 2 days, 4 days, 6 days supernatants of $\mathrm{O} 1$ fermentation cultures. b Category of identified proteins in 2 days, 4 days, 6 days supernatants of 01 fermentation cultures. GH glycoside hydrolase; PL polysaccharide lyase. c Venn diagram of the comparison of identified proteins in 2 days, 4 days, 6 days supernatants of $\mathrm{O} 1$ fermentation cultures. $\mathbf{d} \mathrm{A}$ schematic diagram that roughly displayed the detailed varieties and relative amount of secreted protein by A. niger $\mathrm{O} 1$ after 2 days, 4 days, 6 days cultivation

still different as shown in Additional file 5: Fig. S2. This may be due to different kinds of O-linked glycosylation that cannot be digested by PNGase F [29].

\section{Characterization of each component function of glucoamylases cocktail secreted by $A$. niger strain 01}

In order to optimize the reaction conditions of the starch saccharification, varied reaction $\mathrm{pH}$ and temperatures of each identified enzyme were investigated. As shown in Fig. 3a and b, the optimal pH of the O1-1 (neutral $\alpha$-amylase), O1-2 (low-glycosylated glucoamylase), O1-3 (acid $\alpha$-amylase), and O1-4 (high-glycosylated glucoamylase) are 6.0, 4.4, 4.4 and 4.4, respectively. For O1-2, O1-3 and $\mathrm{O} 1-4$, the activity at the $\mathrm{pH}$ from 4.0 to 5.0 change slightly, but O1-1 shows higher enzyme activity at near neutral $\mathrm{pH}$ (6.0). Therefore, the $\mathrm{pH}$ for further synergistic study of saccharification enzyme system was set up at 5.0. O1-1, O1-2, O1-3 and O1-4 show the highest activity at $50{ }^{\circ} \mathrm{C}, 64{ }^{\circ} \mathrm{C}, 62{ }^{\circ} \mathrm{C}$ and $62{ }^{\circ} \mathrm{C}$, respectively (Fig. 3c and d). O1-4 (glucoamylase) is the most important enzyme in starch scarification, thus the optimal temperature for further study of synergistic degradation of starch was set as the optimal temperature of $\mathrm{O} 1-4\left(62{ }^{\circ} \mathrm{C}\right)$. Considering the other three enzymes showing no obvious decrease in activity at $62{ }^{\circ} \mathrm{C}$, it was finally determined that the reaction temperature of the synergistic enzyme system is $62{ }^{\circ} \mathrm{C}$ and the reaction $\mathrm{pH}$ is 5.0.

\section{Synergistic effect of each enzyme component in glucoamylases cocktail on starch saccharification}

The proportion of different enzymes in the synergistic system was adjusted and optimized based on the proportion in the secreted protein of strain O1 (O1-1:O1-2:O13:O1-4=9.9:10:0.1:80). As shown in Fig. 4a, increasing the amount of $\alpha$-amylase by 5-10 times in vitro led to boosted yield of reducing sugar by $14.2-23.2 \%$. As shown in Fig. $4 \mathrm{~b}$, when less than $1 \%$ acid $\alpha$-amylase was added, the produced reducing sugar increased not more than $3.0 \%$ compared to the original enzyme ratio in glucoamylases cocktail ( $0.1 \%$ acid $\alpha$-amylase). When the supplemented acid $\alpha$-amylase was greater than $8 \%$, the yield of reducing sugar increased obviously. As shown in Fig. 4c, the optimal ratio of O1-2:O1-4 is 40:50. The reducing 


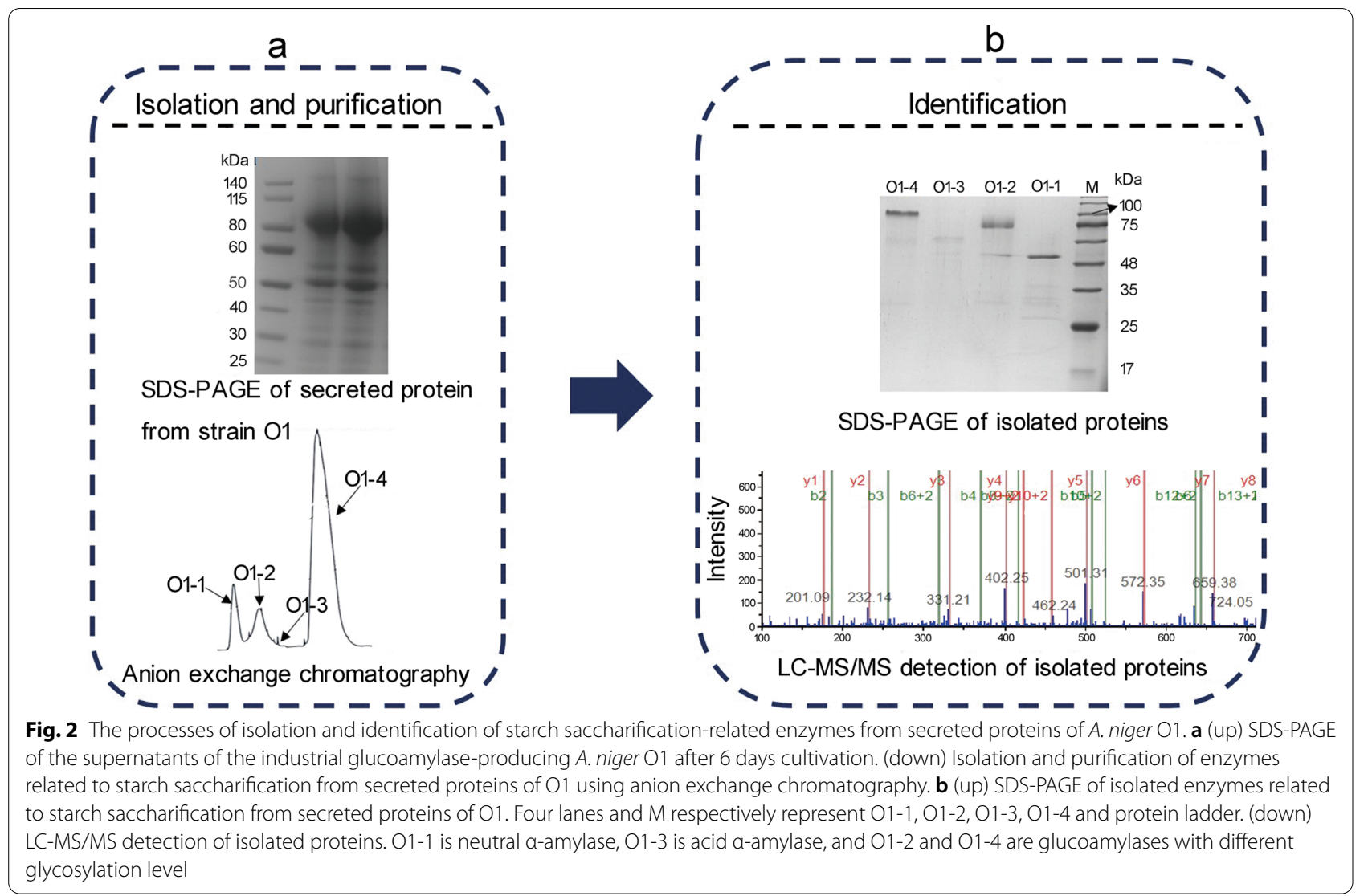

sugar production increased by $8.8-16.6 \%$ when changing the ratio of O1-2:O1-4 from 10:80 to $40: 50$.

\section{The effects of overexpression and knock out of acid a-amylase (AA) gene on the total glucoamylase activity of secreted proteins from 01}

Based on the results of synergistic study, we designed a binary vector for overexpression of acid $\alpha$-amylase gene. The donor DNA and sgRNA cassettes of acid $\alpha$-amylase (O1-3) gene were designed and constructed for CRISPRCas9 gene editing system to knock out acid $\alpha$-amylase gene. After protoplasts transformation, four homozygous AA-OE (overexpression) and four homozygous AA-KO (knock out) transformants were obtained and identified by diagnostic PCR. The supernatants of the 6-day cultures were assayed by SDS-PAGE which shows improved acid $\alpha$-amylase expression in AA-OE strains and disappeared acid $\alpha$-amylase in AA-KO strains compared to host strain $\mathrm{O} 1$ with loading the same amount of total protein (Fig. 5a). This was also verified by the real-time PCR (Additional file 6: Fig. S3a). The concentration of total extracellular protein was detected using the supernatants of 6-day fermentation cultures. The results indicate that $\mathrm{AA}-\mathrm{OE}$ and $\mathrm{AA}-\mathrm{KO}$ strains have similar extracellular protein levels compared with the host stain O1 (Fig. 5b). The total glucoamylase activity of the filtered supernatants of transformants and $\mathrm{O} 1$ were measured. The AA-OE strains (AA-OE-1, AA-OE2, AA-OE-3, AA-OE-8) exhibit significantly higher glucoamylase activity than $\mathrm{O} 1$ by $18.7 \%, 21.7 \%, 8.3 \%$, and $11.1 \%$, respectively (Fig. 5c). The glucoamylase activity of the AA-KO transformants AA-KO-16, AA-KO-36, AA-KO-39 and AA-KO-44 were significantly reduced to $90.9 \%, 82.1 \%, 84.3 \%$ and $85.5 \%$ of that of O1, respectively (Fig. 5c).

\section{The effects of overexpression and knock out of neutral a-amylase (NA) gene on the total glucoamylase activity of secreted proteins from 01}

The experiments for neutral $\alpha$-amylase overexpression and knock out were similarly designed as the acid $\alpha$-amylase overexpression and knock out. Overexpression binary vector and donor DNA, sgRNAs were constructed, respectively, for NA-OE (overexpression) and NA-KO (knock out). After protoplasts transformation, four homozygous NA-OE and two homozygous NA-KO transformants were obtained and identified using diagnostic PCR. The 6-day culture supernatants were assayed 

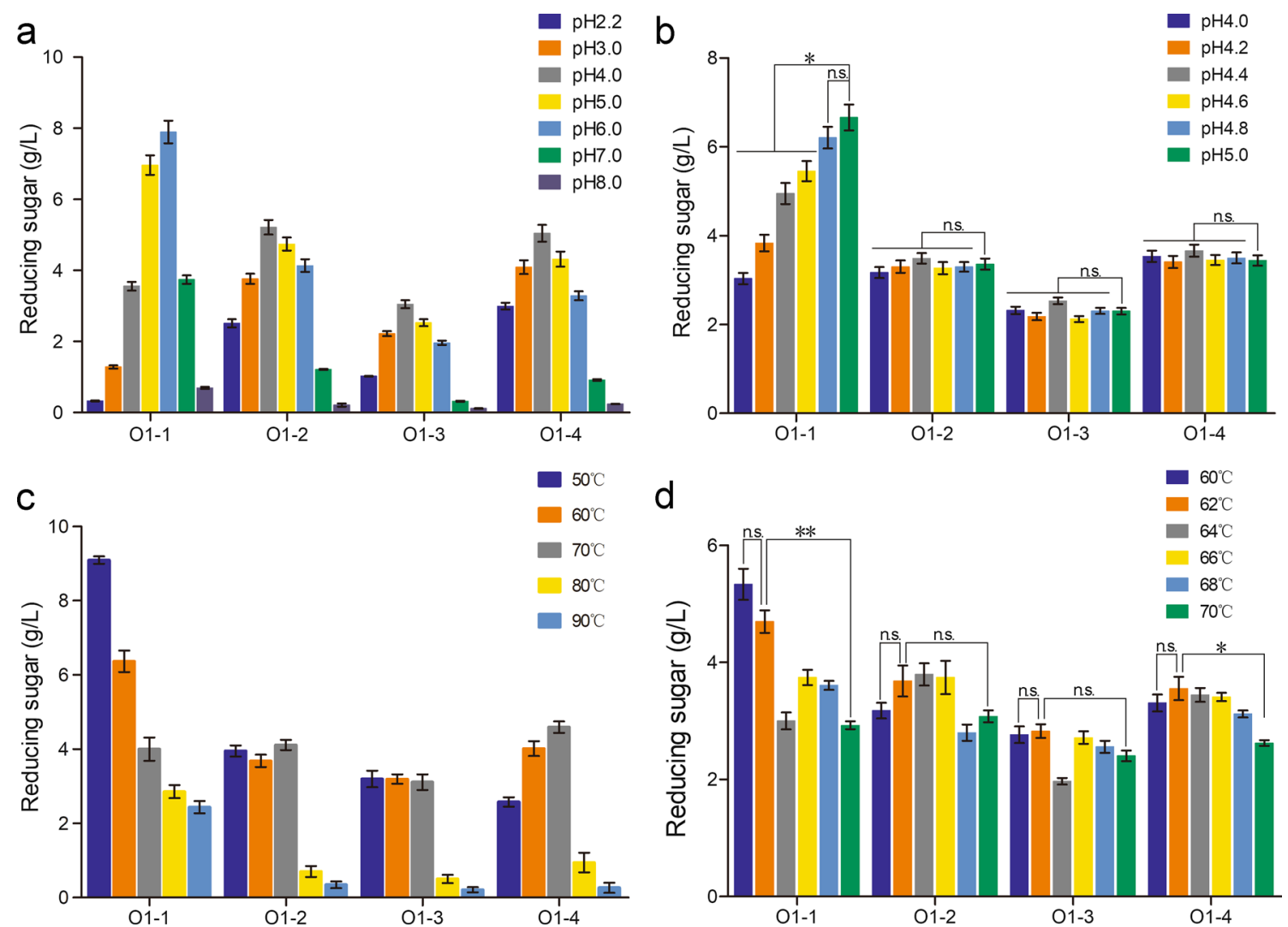

Fig. 3 Characterization of each component function of glucoamylases cocktail secreted from A. niger O1. $\mathbf{a}$ and $\mathbf{b}$ The optimal pH of different starch saccharification-related enzymes. $\mathbf{c}$ and $\mathbf{d}$ The optimal reaction temperature of different starch saccharification-related enzymes. 01-1: neutral a-amylase, O1-2: low-glycosylated glucoamylase, 01-3: acid a-amylase, and 01-4: high-glycosylated glucoamylase. Values are means \pm SD $(n=3$ repeats). ${ }^{*} P<0.01$ (Student's $t$-test), ${ }^{*} P<0.05$ (Student's $t$-test), n.s. not significant

by SDS-PAGE on which NA-OE strains display thicker neutral $\alpha$-amylase band and NA-KO strains show disappeared neutral $\alpha$-amylase band compared to the host strain $\mathrm{O} 1$ with loading the same amount of total protein (Fig. 5d). This was also verified by the real-time PCR (Additional file 6: Fig. S3b). The concentration of total extracellular proteins in 6 days fermentation cultures was also detected. The protein levels of NA-OE-7, NA-OE-23 and NA-OE-31 slightly increased by $6.7 \%$, $5.6 \%$ and $2.6 \%$, and the protein level of NA-OE-33 slightly decreased by $1.3 \%$ than $\mathrm{O} 1$ (Fig. 5e). The protein levels of two NA-KO strains NA-KO-36 and NA-KO-51 significantly decreased by $16.4 \%$ and $17.5 \%$ compared with that of the host strain O1 (Fig. 5e). We also analyzed the total glucoamylase activity of supernatants of four NA-OE strains, two NA-KO strains and O1. Enzymatic assay results exhibit that three of four NA-OE strains have improved enzymatic activity by $13.5 \%, 14.8 \%, 19.6 \%$ and NA-OE-23 has almost the same enzymatic activity as $\mathrm{O} 1$ (Fig. 5f); whereas, the glucoamylase activity of two
NA-KO strains significantly reduced to $87.6 \%$ and $76.0 \%$ of that of the host strain O1 (Fig. 5f).

\section{Discussion}

Starch saccharification is the important step for production of high value-added downstream industry products, such as bio-ethanol, amino acids, pharmaceuticals [15, 30,31]. The efficiency of saccharification process depends on the total glucoamylase activity. Glucoamylase used in industry is not a single enzyme, but a mixture of various starch-degrading enzymes. All enzymes playing roles in starch saccharification constitute a glucoamylase enzyme system in which the glucoamylase is the major functional enzyme. However, the exact contributions of each of these enzymes during the starch saccharification working with glucoamylase remain unclear.

In our study, we tried to dig up more enzymes associated with starch saccharification from industrial strain A. niger $\mathrm{O} 1$ and study their secreted proteome profiles during fermentation process for glucoamylases system production. We found that glycoside hydrolases detected 

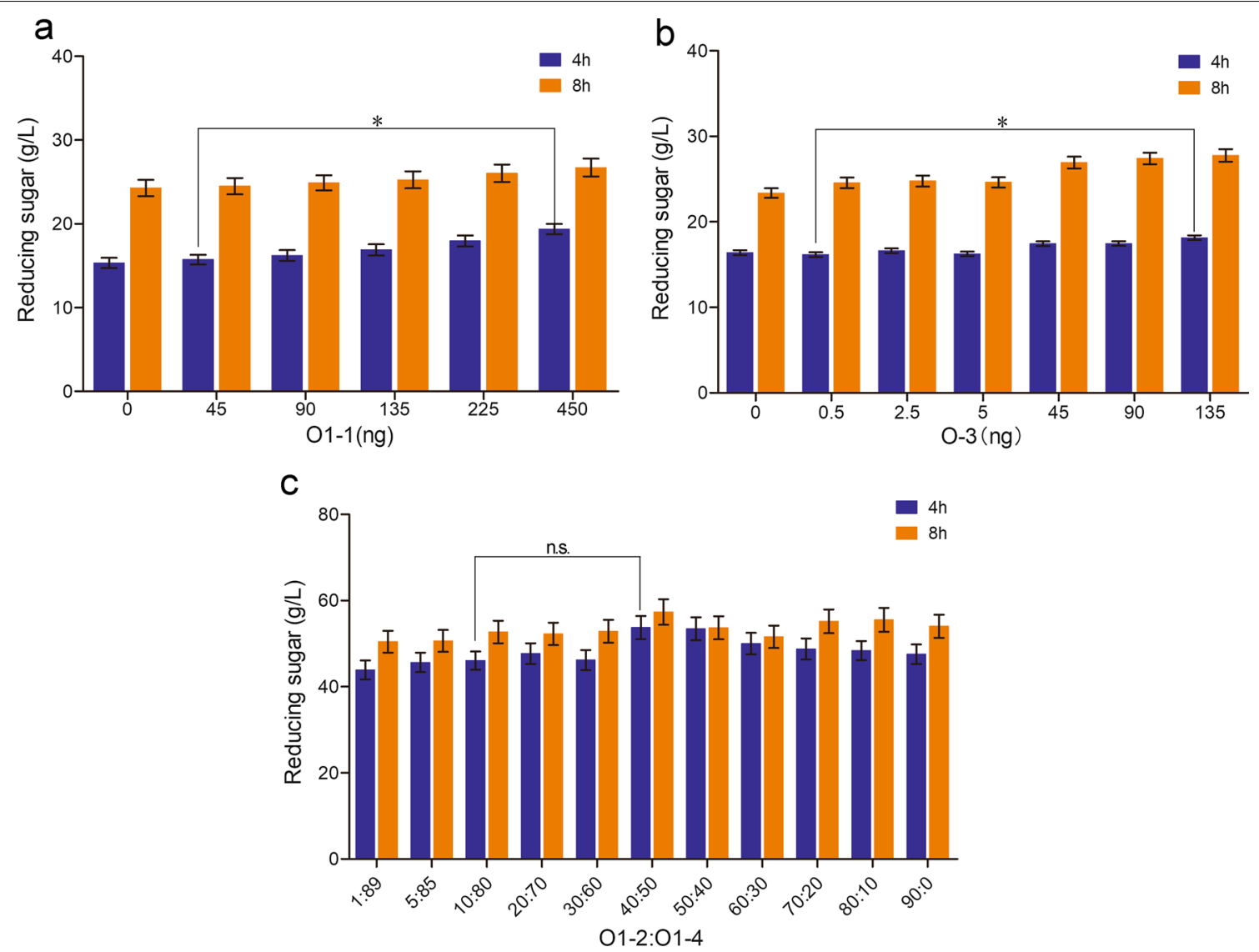

Fig. 4 Synergistic effects of each enzyme component in glucoamylases cocktail on starch saccharification. a The effect of O1-1 neutral a-amylase on glucoamylases cocktail for starch saccharification. $\mathbf{b}$ The effect of 01-3 acid a-amylase on glucoamylases cocktail for starch saccharification. $\mathbf{c}$ The effect of the ratio of two glucoamylases on glucoamylases cocktail for starch saccharification. Values are means $\pm S D\left(n=3\right.$ repeats). ${ }^{*} P<0.05$ (Student's t-test), n.s. not significant

in secreted proteome increased from 2 to 6 days fermentation cultures during the whole fermentation process (Fig. 1b). The three proteins accounting for the highest amount (glucoamylase, $\alpha$-amylase and acid $\alpha$-amylase) belong to glycoside hydrolase families and are involved in starch saccharification (Fig. 1d). The other two enzymes (catalase and aspartate aminotransferase) in fermentation cultures might be important for growth of strain O1, but not for starch degradation. Additionally, endoglucanase $\mathrm{A}$ is an enzyme belonging to GH12 with the annotation of cellulase activity. Although $\alpha$-glucosidase is a starchdegrading glycoside hydrolase in fermentation cultures, it is undesirable for starch saccharification because of its transglycosylation activity for producing unfermentable sugars [32-34]. Other glycoside hydrolases detected in fermentation supernatants are related to the degradation of other polysaccharides not starch (Additional file 1: Fig. S1). So glucoamylase, $\alpha$-amylase and acid $\alpha$-amylase are the main components in glucoamylase enzyme system of industrial strain $\mathrm{O} 1$ for starch saccharification.
Four main protein components were isolated from the supernatants of the 6-day fermentation cultures and named as O1-1, O1-2, O1-3 and O1-4. LC-MS/MS detection and enzymatic activity assay confirmed the specific ingredients of four isolated proteins: neutral $\alpha$-amylase (O1-1), low-glycosylated glucoamylase (O1-2), acid $\alpha$-amylase (O1-3) and high-glycosylated glucoamylase (O1-4) (Fig. 2a and b). Characterization of four enzymes confirmed the optimal temperature and the optimal $\mathrm{pH}$ : O1-1 (50 $\left.{ }^{\circ} \mathrm{C}, \mathrm{pH} 5.0\right), \mathrm{O} 1-2\left(64{ }^{\circ} \mathrm{C}, \mathrm{pH} 4.4\right), \mathrm{O} 1-3\left(62{ }^{\circ} \mathrm{C}\right.$, $\mathrm{pH} 4.4), \mathrm{O} 1-4$ (62 $\left.{ }^{\circ} \mathrm{C}, \mathrm{pH} 4.4\right)$, respectively (Fig. 3a-d). These results provided the optimal reaction conditions for the glucoamylase enzyme system of strain $\mathrm{O} 1\left(62{ }^{\circ} \mathrm{C}\right.$, $\mathrm{pH}$ 5.0). The in vitro synergistic effects analysis showed that the 10 times increased neutral $\alpha$-amylase or acid $\alpha$-amylase improved the saccharification efficiency of soluble starch by $8.0-23.2 \%$ (Fig. 4a, b).

As we all know, traditional method used for the production of glucose from starch usually requires two steps: liquefaction via thermostable neutral- $\alpha$-amylase at $\mathrm{pH}$ 

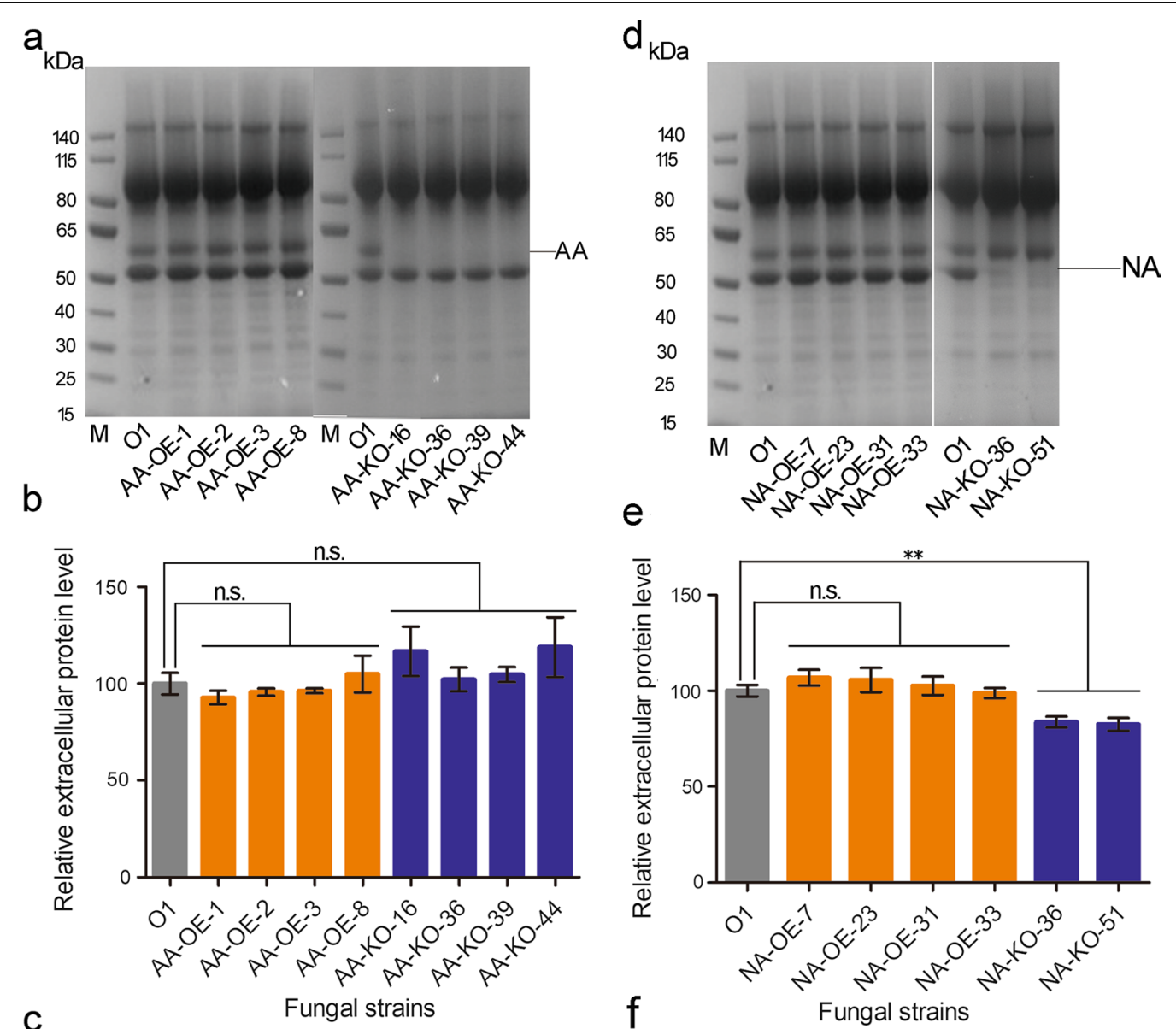

C

Fungal strains

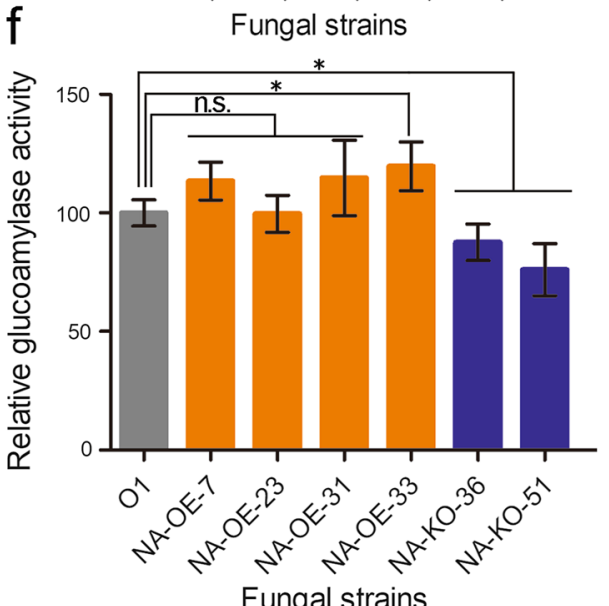

Fig. 5 The effects of overexpression and knock out of acid a-amylase (AA) and a-amylase (NA) genes on protein expression level and total glucoamylase activity. a SDS-PAGE analysis of secreted proteins in 6-day supernatants of fermentation cultures of A. niger O1, AA-OE and AA-KO strains. b Extracellular protein level detection in 6-day supernatants of fermentation cultures of A. niger O1, AA-OE and AA-KO strains. Relative extracellular protein level = Extracellular protein level of engineered strain to that of O1. c The total glucoamylase activity assay in 6-day supernatants of fermentation cultures of A. niger O1, AA-OE and AA-KO strains. Relative glucoamylase activity=glucoamylase activity of engineered strain to that of O1.d SDS-PAGE analysis of secreted proteins in 6 days supernatants of fermentation cultures of A. niger O1, NA-OE and NA-KO strains. e Extracellular protein level detection in 6 days supernatants of fermentation cultures of A. niger O1, NA-OE and NA-KO strains. Relative extracellular protein level= extracellular protein level of engineered strain to that of O1.f The total glucoamylase activity assay in 6 days supernatants of fermentation cultures of A. niger O1, NA-OE and NA-KO strains. The total glucoamylase activities of transformants and O1 were measured using the same amount of total protein in supernatants. Relative glucoamylase activity=glucoamylase activity of engineered strain to that of 01 . Values are means $\pm S D\left(n=3\right.$ repeats). ${ }^{*} P<0.01$ (Student's $t$-test), ${ }^{*} P<0.05$ (Student's $t$-test), n.s. not significant 
6.0 and $80-115{ }^{\circ} \mathrm{C}$ for dextrin production and saccharification by glucoamylase at $\mathrm{pH} 4.2-4.5$ and $60-70{ }^{\circ} \mathrm{C}$ for glucose production from dextrin [23]. $\mathrm{pH}$ and temperature changes from the liquefaction step to saccharification step result in the high cost in two-step enzymatic hydrolysis of starch [19]. Previous studies focused mostly on the neutral $\alpha$-amylases in liquefaction step, while acid $\alpha$-amylase was not investigated much for liquefaction step [13, 22, 35]. Because acid $\alpha$-amylase has comparable reaction condition with glucoamylase, the replacement of neutral amylase by acid $\alpha$-amylase can change the twostep procedure to one step (simultaneously liquefaction and saccharification in one pot) which leads to the reduction of the time and the cost. Usually, glucoamylases used in industry are glycosylated which can enhance the enzyme stability [36]. Hence, changing the ratio of lowglycosylated and high-glycosylated glucoamylases seems to be a feasible solution to enhance the total glucoamylase activity during the whole process of saccharification. As described, changing the ratio of O1-2:O1-4 from 10:80 to 40:50 leads to the increase of the reducing sugar by $8.8-16.6 \%$. However, many factors affect glucoamylase glycosylation in vivo, therefore it is difficult to control the ratio of glucoamylase at different glycosylation levels [37, 38].

The total extracellular protein levels in the fermentation cultures of AA-OE and NA-OE strains did not show obvious increase compared with that of the strain O1, but the protein expressions of acid $\alpha$-amylase and $\alpha$-amylase are enhanced (Fig. 5a, d). Fermentation cultures of NA-KO strains without $\alpha$-amylase expression show expected decrease of the extracellular protein levels compared with that of the host strain O1 (Fig. 5e). However, fermentation cultures of AA-KO strains without acid $\alpha$-amylase expression have no obvious change in extracellular protein levels compared with that of host strain O1 (Fig. 5b). Based on the rough ratio of four isolated and purified proteins, extracellular $\alpha$-amylase and acid $\alpha$-amylase account for about $10 \%$ and $0.1 \%$ of the total extracellular protein (Fig. 2a). We speculate the extracellular protein levels of NA-KO strains were affected more than that of the AA-KO strains. The total glucoamylase activity of both AA-OE and NA-OE strains were all improved compared with that of the host strain O1 (Fig. 5c, f). However, the enhancement of enzymatic activity in AA-OE strains were more obvious than NA-OE strains. On the contrary, the total glucoamylase activity of both AA-KO and NA-KO strains decreased significantly (Fig. 5c, f). However, the enhancement of enzymatic activity in AA-OE strains were more obvious than NA-OE strains, which is different from the results of in vitro synergistic studies that NA had higher effect than AA. This might be due to the limitation of the purification methods, and the amount of AA obtained is less than the amount present in the cultures, so it may reduce the role of AA in in vitro synergistic studies. These results prove that $\alpha$-amylase and acid $\alpha$-amylase are necessary for maintaining the total glucoamylase activity, and the absence of acid $\alpha$-amylase or $\alpha$-amylase results in a remarkable decrease on the total glucoamylase activity. Generally, $\alpha$-amylase and acid $\alpha$-amylase together with glucoamylase convert starch into monosaccharides in industry. $\alpha$-Amylase, acid $\alpha$-amylase and glucoamylase exert synergistic effects on the hydrolysis of starch. Overexpression of $\alpha$-amylase and acid $\alpha$-amylase provides more non-reducing ends for glucoamylase, and then increases the catalytic efficiency of the glucoamylase enzyme system. Through the synergistic study of the multi-enzymes in the glucoamylase enzyme system in vitro, we found the increases of $\alpha$-amylase from 9 to $23 \%$ or acid $\alpha$-amylase from 0.1 to $8 \%$ can obviously enhance the efficiency of starch saccharification. Obvious effects were also observed in the supernatants of $\alpha$-amylase or acid $\alpha$-amylase overexpression strains even if without such high increases of these two enzymes. These may be because some less amount components waiting to be identified in supernatants of fermentation that has important synergistic effects with enzymes in glucoamylase enzyme system, although it is not likely all over 78 proteins identified by LC-MS/MS will have positive effect on the total glucoamylases activity, some of them might be, which is worth analyzing further in the future. Generally, increasing the $\alpha$-amylase especially acid $\alpha$-amylase expression can significantly improve the total glucoamylase activity.

\section{Conclusion}

In this study, glucoamylase, $\alpha$-amylase and acid $\alpha$-amylase were identified as the main saccharifying enzymes in strain $\mathrm{O} 1$ for starch hydrolysis. Moreover, the synergistic study revealed that adjusting the ratio of the key saccharifying enzymes could improve the total glucoamylase activity of glucoamylase enzyme system. Furthermore, adjusting the ratio of key saccharifying enzymes secreted from strain $\mathrm{O} 1$ by genetic manipulation enhanced the starch saccharification efficiency of the glucoamylase enzyme system.

\section{Methods}

\section{Strains, media and growth conditions}

Aspergillus niger glucoamylase-producing industrial strain $\mathrm{O} 1$ with aconidial phenotype provided by Longda Biotechnology Inc. (Shandong, China). All the transformants were obtained by protoplast-mediated transformation. Strain O1 and transformants were cultivated at $34{ }^{\circ} \mathrm{C}$ using Czapek-Dox solid medium. The composition of Czapek-Dox solid medium is as follows 
(g/L): sucrose (30), $\mathrm{NaNO}_{3}$ (2), $\mathrm{MgSO}_{4} \cdot 7 \mathrm{H}_{2} \mathrm{O}$ (1.02), $\mathrm{KCl}(0.5), \mathrm{FeSO}_{4} \cdot 7 \mathrm{H}_{2} \mathrm{O}(0.0183), \mathrm{K}_{2} \mathrm{HPO}_{4}(1)$, agar (15), $\mathrm{pH}$ 6.0. Shake-flask medium contains $100 \mathrm{~g} / \mathrm{L}$ glucose, $30 \mathrm{~g} / \mathrm{L}$ soybean flour and $30 \mathrm{ml} / \mathrm{L}$ corn steep liquor ( $\mathrm{pH}$ 5.6). Moderate amount of mycelium was inoculated into $50 \mathrm{~mL}$ fermentation medium in a $250-\mathrm{mL}$ Erlenmeyer flask. Shake-flask fermentation was performed at $34{ }^{\circ} \mathrm{C}, 240 \mathrm{rpm}$ for 6 days. 2-day, 4-day and 6 -day culture supernatants were collected and used for secreted proteome, protein concentration and glucoamylase activity analysis. Escherichia coli DH5 $\alpha$ was used for plasmid proliferation and was cultured at $37{ }^{\circ} \mathrm{C}$ in Luria-Bertani (LB) medium added with kanamycin or ampicillin $(100 \mathrm{mg} / \mathrm{L})$.

\section{Construction of the plasmids for overexpression and deletion of a-amylase or acid $a$-amylase gene}

The primers used in this study are listed in Additional file 3: Table S1. The $\alpha$-amylase gene (ANI_1_260044) was amplified using the primers An-amyA-SpeIF/An-amyA-EcoRI-R and acid $\alpha$-amylase gene (ANI_1_460094) was amplified using the primers AnamyB-SpeI-F/An-amyB-EcoRV-R from Aspergillus niger O1 genomic DNA. Then the identified fragments of $\alpha$-amylase and acid $\alpha$-amylase gene were, respectively, linked to SpeI/EcoRI- and SpeI/EcoRV-digested PAN52AnPtef-TtrpC vector using T4 DNA ligase to finish the construction of overexpression plasmids.

For the deletion of the $\alpha$-amylase and acid $\alpha$-amylase gene, gene deletion substrates were constructed. the $5^{\prime}$ and $3^{\prime}$-flanking sequences of ANI_1_260044 and ANI_1_460094 were amplified using the primers 2amyA-donor-F1/R1, 2amyA-donor-F3/R3 and amyBdonor-F1/R1, amyB-donor-F3/R3, respectively. PtrpCneo cassette was amplified from P0380-neo using the primers 2amyA-donor-F2/R2 and amyB-donor-F2/R2 for $\alpha$-amylase and acid $\alpha$-amylase gene deletion, respectively. The fragment $5^{\prime}$-PtrpC-neo-3' was integrated by overlapping PCR and cloned into the Pjet1.2/blunt cloning vector to generate donor DNA sequences. Specific sgRNAs targeting $\alpha$-amylase and acid $\alpha$-amylase genes were designed using the sgRNACas9 tool and sgRNA target sites with high scores were selected. All protospacer sequences used to target the genes are presented in Additional file 4. U6 promoter was amplified from the genome of $A$. niger O1. sgRNAs and sgRNA scaffold fragment were fused by overlapping PCR. The final resulting fusion fragments were cloned into Pjet1.2/blunt cloning vector for sequencing. The Cas9-expression PCR cassette AnPtef-Cas9-TtrpC was amplified using primers from the plasmid P0380AnPtef-Cas9-TtrpC constructed in our lab.

\section{Transformation of $A$. niger protoplasts}

Transformation of $A$. niger protoplasts was performed according to a previously described procedure with some modifications [39]. For target gene expression, $10 \mu \mathrm{g}$ linearized plasmid was added to the fungal protoplasts. For gene disruption by the CRISPR/Cas9 system, $10 \mu \mathrm{g}$ Cas9expression cassette AnPtef-Cas9-TtrpC, sgRNA expression cassettes and the corresponding donor fragments were mixed with a molar concentration ratio of 1:1:1 and then added to fungal protoplasts [40]. The transformants were cultivated on $\mathrm{MM}$ medium at $34{ }^{\circ} \mathrm{C}$ for 3 days with selected resistance geneticin $(250 \mathrm{mg} / \mathrm{L}) . \alpha$-Amylase and acid $\alpha$-amylase overexpression or disruption strains were confirmed through diagnostic PCR.

\section{Total RNA extraction and quantitative real-time PCR}

The mycelia after 6-day shake-flask cultivation were harvested by vacuum filtration, and then homogenized in liquid nitrogen for total RNA extraction. Total RNA was isolated and purified using a Qiagen RNeasy Mini Kit (Qiagen, Hilden, Germany). Total RNA was synthesized to first strand cDNA using ReverTra Ace qPCR RT Kit (TOYOBO, Osaka, Japan). qRT-PCR was performed with SYBR Green Real-time PCR Master Mix (TOYOBO, Osaka, Japan). The primers used for genes are listed in Additional file 3: Table S1. The actin gene (ANI_1_106134) was used as an internal control. The reaction system and reaction condition were carried out as previously described [40]. The expression level of each gene was estimated using the $2^{-\Delta \Delta \mathrm{CT}}$ method [41]. The transcription level in each transformant to that in the $\mathrm{O} 1$ strain was calculated as the relative expression level.

\section{Glucoamylase enzymatic activity assay}

The glucoamylase activity was determined by a modified 3,5-dinitrosalicylic acid method using soluble starch as the substrate. Briefly, $25 \mu \mathrm{L}$ of $8 \%$ soluble starch mixed with $25 \mu \mathrm{L} 100 \mathrm{mM}$ citrate-phosphate buffer, $\mathrm{pH}$ 5.0. The mixture was incubated at $62{ }^{\circ} \mathrm{C}$ for $5 \mathrm{~min}$ followed by the addition of $50 \mu \mathrm{L}$ moderately diluted culture supernatant for further $10 \mathrm{~min}$ incubation. Subsequently, $150 \mu \mathrm{L}$ dinitrosalicylic acid was added to stop the reaction. Then, the samples were boiled for $7 \mathrm{~min}$ and $1 \mathrm{~mL}$ distilled water was added. The glucoamylase activity was subsequently evaluated by measuring the reducing sugars released from starch hydrolysis at $550 \mathrm{~nm}$.

\section{Secretome analysis by liquid chromatography-tandem mass spectrometry (LC-MS/MS)}

$A$. niger $\mathrm{O} 1$ was cultured in fermentation medium and the cultures of 2 days, 4 days and 6 days were collected. The cultures were centrifuged and then filtered through 
a $0.22-\mu \mathrm{m}$ PES membrane (Millipore). Protein concentrations of the culture supernatants were determined using Bradford assay (Bio-Rad Laboratories, CA) with bovine serum albumin (BSA) as standard according to the manufacturer's instructions. The supernatants of 2 days, 4 days, 6 days cultures were assayed by SDS-PAGE. Then, the SDS-PAGE gel was cut into small pieces. In-gel protein digestion was performed following the previously published protocol [42]. The LC-MS/MS analysis was performed with an Eksigent Nano LC coupled to TripleTOF 5600 mass spectrometer (SCIEX, USA) with a nanoelectrospray ionization source [43]. The top 40 precursor ions with the most intensity were fragmented with $22 \mathrm{~s}$ of dynamic exclusion time. The WIFF files from shotgun data acquisition were searched against the Uniprot database of Aspergillus niger (strain CBS 513.88/FGSC A1513, 2020.04, 14084 entries) in MaxQuant (ver. 1.6.3.4) search engine [44]. Trypsin was set as the specific enzyme, and up to two missed cleavages per peptide were allowed. Precursor ion mass tolerance was set to $20 \mathrm{ppm}$ and fragment ion tolerance was $0.05 \mathrm{Da}$. For protein identification, the peptide false discovery rates (FDR) were set at $1 \%$.

\section{Isolation, purification, and identification of starch saccharification-related enzymes from the secreted proteins of $A$. niger 01}

The filtered supernatant was desalted by Amicon ${ }^{\circledR}$ ultracentrifugal filter (membrane with cut-off size of $5 \mathrm{kDa}$ ). Subsequently, the desalted supernatant was applied to anion exchange column (HiTrap Q HP, $5 \mathrm{~mL}$, GE) previously equilibrated with buffer A $(20 \mathrm{mM}$ potassium phosphate, $\mathrm{pH}$ 7.0). The proteins that bind to the column were firstly washed with $0 \%$ buffer $\mathrm{B}(20 \mathrm{mM}$ potassium phosphate, $250 \mathrm{mM} \mathrm{NaCl}, \mathrm{pH} 7.0$ ) at a flow rate of $2 \mathrm{~mL} /$ min to remove some impurities. Buffer B was increased from 0 to $100 \%$ in $60 \mathrm{~min}$ at a flow rate of $3 \mathrm{~mL} / \mathrm{min}$ to elute proteins and the eluted fractions were collected with 96 -well deep-hole plates $(1.8 \mathrm{~mL} /$ well). The eluted fractions corresponding to each UV peak were monitored using SDS-PAGE. The fractions corresponding to each pure band on SDS-PAGE gel were applied for protein identification using LC-MS/MS. The concentration of purified enzyme was determined by Braford assay kit using BSA as standard. The purified enzyme liquid was frozen and dried into powder and stored at $-80{ }^{\circ} \mathrm{C}$ for further use.

\section{Characterization of each component function of glucoamylases cocktail secreted from $A$. niger 01}

The activity of each enzyme for real substrate (starch) was determined as follows: $50 \mu \mathrm{L} 100 \mathrm{ng} / \mu \mathrm{L}$ enzyme protein, $25 \mu \mathrm{L} 8 \%$ starch (after boiling treatment), $25 \mu \mathrm{L}$
$100 \mathrm{mM}$ citrate phosphate buffer ( $\mathrm{pH}$ 5.0). After incubation at $60{ }^{\circ} \mathrm{C}$ for $10 \mathrm{~min}$, the yield of reducing sugar was measured by DNS method [45]. The optimal $\mathrm{pH}$ of each enzyme was measured in $100 \mathrm{mM}$ citrate phosphate buffer with different $\mathrm{pH}(2.2,3.0,4.0,4.2,4.4,4.6,4.8$, 5.0, 6.0, 7.0, and 8.0). The optimal reaction temperature of each enzyme was measured at different temperatures $\left(50,60,62,64,66,68,70,80,90^{\circ} \mathrm{C}\right)$ and $\mathrm{pH}$ 5.0. Deglycosylation of O1-2 and O1-4 was conducted with PNGase $\mathrm{F}$ (peptide- $N$-Glycosidase F) as described in the manual instruction.

\section{Synergistic effects of the multiple saccharifying enzymes on starch saccharification}

The synergistic reactions of multiple saccharifying enzymes were carried out at $62{ }^{\circ} \mathrm{C}$ for 4 and $8 \mathrm{~h}$, and the reducing sugars produced were measured using DNS assay. In order to monitor the effect of neutral $\alpha$-amylase in synergistic system on starch saccharification, different concentrations of neutral $\alpha$-amylase $(0,112.5,225$, $337.5,562.5,1125 \mathrm{ng} / \mathrm{mL}$ ) were added in the reaction system containing $10 \%$ starch, $125 \mathrm{ng} / \mathrm{mL}$ low-glycosylated glucoamylase, $1000 \mathrm{ng} / \mathrm{mL}$ high-glycosylated glucoamylase and $1.25 \mathrm{ng} / \mathrm{mL}$ acid $\alpha$-amylase in $100 \mathrm{mM}$ citrate phosphate buffer ( $\mathrm{pH}$ 5.0). For detecting the effect of acid $\alpha$-amylase in synergistic system on starch saccharification, different concentrations of acid $\alpha$-amylase $(0$, $1.25,6.25,12.5,112.5,225,337.5 \mathrm{ng} / \mathrm{mL}$ ) were added in the reaction system containing $10 \%$ starch, $125 \mathrm{ng} / \mathrm{mL}$ low-glycosylated glucoamylase, $1000 \mathrm{ng} / \mathrm{mL}$ high-glycosylated glucoamylase and $125 \mathrm{ng} / \mathrm{mL}$ neutral $\alpha$-amylase in $100 \mathrm{mM}$ citrate phosphate buffer (pH 5.0). The optimum ratio of two glucoamylases was also measured. The reaction system contained $10 \%$ starch, $50 \mathrm{ng} / \mathrm{mL}$ neutral $\alpha$-amylase, $5 \mathrm{ng} / \mathrm{mL}$ acid $\alpha$-amylase and $4500 \mathrm{ng} / \mathrm{mL}$ total glucoamylase with different ratios $(1: 89,5: 85,10: 80$, $20: 70,30: 60,4050,50: 40,60: 30,70: 20,80: 10,90: 0)$ in $100 \mathrm{mM}$ citrate phosphate buffer (pH 5.0).

\section{Supplementary Information}

The online version contains supplementary material available at https://doi. org/10.1186/s13068-021-02074-x.

Additional file 1: Figure S1. Glycoside hydrolases and relative abundance detected in 2d, 4d and $6 \mathrm{~d}$ fermentation supernatants.

Additional file 2 . The results of the peptide fragments of 01-1, 01-2, 01-3 and 01-4 searched against the Uniprot database of Aspergillus niger.

Additional file 3: Table S1. List of PCR primers used in this study. Additional file 4. Nucleotide sequences of the sgRNA expression cassettes.

Additional file 5: Figure S2. Electrophoretic analysis of purified $01-2$ and 01-4 with or without digestion with peptide-N-glycosidase F. 1. Before 
deglycosylation of O-4, 2. After deglycosylation of O-4, 3. Before deglycosylation of O-2, 4. After deglycosylation of O-2.

Additional file 6: Figure $\mathbf{S 3}$. Relative transcription level of acid a-amylase (AA) and a-amylase (NA) genes in 01 strain and transformants. a Relative transcription level of AA in stain $\mathrm{O} 1$ and $\mathrm{AA}$-overexpression and AA knock out transformants. b Relative transcription level of NA in stain $\mathrm{O} 1$ and NAoverexpression and NA knock out transformants.

\section{Acknowledgements}

We thank Qichen Cao in Tianjin Institute of Industrial Biotechnology, Chinese Academy of Sciences, for assistance in secreted proteome detection and analysis.

\section{Authors' contributions}

$C T$ and $L Z$ designed the project. WG, JY, TH, DL performed the experiments. WG, JY, QL, JL and WS analyzed the data. XW provided the $\mathrm{O} 1$ strain and guided the strain cultivation. WG and JY wrote the manuscript. CT and LZ revised and improved the manuscript. All authors read and approved the final manuscript.

\section{Funding}

This study was financially supported by the National Key Research and Development Program of China (Grant No. 2018YFA0902200), the Tianjin Synthetic Biotechnology Innovation Capacity Improvement Project (Grant No. TSBICIPKJGG-006), and the National Natural Science Foundation of China (Grant Nos. 31901066, 31972879, 31771386, 31972878, 32071424).

\section{Availability of data and materials}

All the supporting data are available.

\section{Declarations}

\section{Ethics approval and consent to participate}

Not applicable.

\section{Consent for publication}

Not applicable.

\section{Competing interests}

The authors declare that they have no competing interests.

\section{Author details}

${ }^{1}$ Key Laboratory of Systems Microbial Biotechnology, Tianjin Institute of Industrial Biotechnology, Chinese Academy of Sciences, Tianjin 300308, China. ${ }^{2}$ National Technology Innovation Center of Synthetic Biology, Tianjin 300308 , China. ${ }^{3}$ Longda Biotechnology Inc, Shandong 276400, China.

Received: 20 August 2021 Accepted: 13 November 2021 Published online: 27 November 2021

\section{References}

1. Kumar P, Satyanarayana T. Microbial glucoamylases: characteristics and applications. Crit Rev Biotechnol. 2009:29:225-55.

2. Zeeman SC, Kossmann J, Smith AM. Starch: its metabolism, evolution, and biotechnological modification in plants. Annu Rev Plant Biol. 2010;61:209-34.

3. Zeeman SC, Smith SM, Smith AM. The breakdown of starch in leaves. New Phytol. 2004;163:247-61.

4. Seung D. Amylose in starch: towards an understanding of biosynthesis, structure and function. New Phytol. 2020;228:1490-504.

5. Nekiunaite L, Arntzen MO, Svensson B, Vaaje-Kolstad G, Abou HM. Lytic polysaccharide monooxygenases and other oxidative enzymes are abundantly secreted by Aspergillus nidulans grown on different starches. Biotechnol Biofuels. 2016;9:187.
6. Wang BT, Hu S, Yu XY, Jin L, Zhu YJ, Jin FJ. Studies of cellulose and starch utilization and the regulatory mechanisms of related enzymes in fungi. Polymers (Basel). 2020;12:530.

7. van Munster JM, Daly P, Blythe MJ, Ibbett R, Kokolski M, Gaddipati S, Lindquist E, Singan VR, Barry KW, Lipzen A, et al. Succession of physiological stages hallmarks the transcriptomic response of the fungus Aspergillus niger to lignocellulose. Biotechnol Biofuels. 2020;13:69.

8. Bellaouchi R, Abouloifa H, Rokni Y, Hasnaoui A, Ghabbour N, Hakkou A, Bechchari A, Asehraou A. Characterization and optimization of extracellular enzymes production by Aspergillus niger strains isolated from date by-products. J Genet Eng Biotechnol. 2021;19:50.

9. Sui YF, Ouyang LM, Schutze T, Cheng S, Meyer V, Zhuang YP. Comparative genomics of the aconidial Aspergillus niger strain LDM3 predicts genes associated with its high protein secretion capacity. Appl Microbiol Biot. 2020;104:2623-37.

10. Cairns TC, Barthel L, Meyer V. Something old, something new: challenges and developments in Aspergillus niger biotechnology. Essays Biochem. 2021;65:213-24.

11. Salgado-Bautista D, Volke-Sepulveda T, Figueroa-Martinez F, CarrascoNavarro U, Chagolla-Lopez A, Favela-Torres E. Solid-state fermentation increases secretome complexity in Aspergillus brasiliensis. Fungal Biol. 2020;124:723-34

12. Cao WQ, Wang G, Lu HZ, Ouyang LM, Chu J, Sui YF, Zhuang YP. Improving cytosolic aspartate biosynthesis increases glucoamylase production in Aspergillus niger under oxygen limitation. Microb Cell Fact. 2020;19:81.

13. van der Maarel MJ, van der Veen B, Uitdehaag JC, Leemhuis H, Dijkhuizen $\mathrm{L}$. Properties and applications of starch-converting enzymes of the alphaamylase family. J Biotechnol. 2002;94:137-55.

14. Sharma A, Satyanarayana T. Microbial acid-stable a-amylases: Characteristics, genetic engineering and applications. Process Biochem. 2013:48:201-11.

15. Xu QS, Yan YS, Feng JX. Efficient hydrolysis of raw starch and ethanol fermentation: a novel raw starch-digesting glucoamylase from Penicillium oxalicum. Biotechnol Biofuels. 2016;9:216.

16. Sundarram A, Murthy TPK. a-Amylase production and applications: a review. J Appl Environ Microbiol. 2014;2:166-75.

17. Gupta R, Gigras P, Mohapatra H, Goswami VK, Chauhan B. Microbial a-amylases: a biotechnological perspective. Process Biochem. 2003;38:1599-616.

18. Rana N, Walia A, Gaur A. a-Amylases from microbial sources and its potential applications in various industries. Natl Acad Sci Lett. 2013;36:9-17.

19. Hua H, Luo H, Bai Y, Wang K, Niu C, Huang H, Shi P, Wang C, Yang P, Yao B. A thermostable glucoamylase from Bispora sp. MEY-1 with stability over a broad pH range and significant starch hydrolysis capacity. PLoS ONE. 2014;9:e113581.

20. Izmirlioglu G, Demirci A. Strain selection and medium optimization for glucoamylase production from industrial potato waste by Aspergillus niger. J Sci Food Agric. 2016;96:2788-95.

21. Kumar P, Satyanarayana T. Optimization of culture variables for improving glucoamylase production by alginate-entrapped Thermomucor indicae seudaticae using statistical methods. Bioresource Technol. 2007;98:1252-9.

22. An X, Ding CJ, Zhang H, Liu TQ, Li J. Overexpression of amyA and glaA substantially increases glucoamylase activity in Aspergillus niger. Acta Bioch Bioph Sin. 2019;51:638-44.

23. Liu YL, Wang FX, Yu J, Li XH, Wang JH. Comparison and analysis of acid-stable and acid-unstable a-amylases from Aspergillus niger with computer. Adv Mater Res. 2012;554-556:1021-4.

24. Marín-Navarro J, Polaina J. Glucoamylases: structural and biotechnological aspects. Appl Microbiol Biot. 2011;89:1267-73.

25. Fujii M, Kawamura Y. Synergistic action of alpha-amylase and glucoamylase on hydrolysis of starch. Biotechnol Bioeng. 1985;27:260-5.

26. Parashar D, Satyanarayana T. Engineering a chimeric acid-stable alphaamylase-glucoamylase (Amy-Glu) for one step starch saccharification. Int J Biol Macromol. 2017;99:274-81.

27. Wang BW, Wu Q, Xu Y, Sun BG. Synergistic effect of multiple saccharifying enzymes on alcoholic fermentation for Chinese Baijiu production. Appl Environ Microbiol. 2020;86:e00013-20.

28. Yoshizaki Y, Susuki T, Takamine K, Tamaki H, Ito K, Sameshima Y. Characterization of glucoamylase and alpha-amylase from Monascus anka: 
enhanced production of alpha-amylase in red koji. J Biosci Bioeng. 2010;110:670-4.

29. Wallis GL, Swift RJ, Hemming FW, Trinci AP, Peberdy JF. Glucoamylase overexpression and secretion in Aspergillus niger: analysis of glycosylation. Biochim Biophys Acta. 1999;1472:576-86.

30. Palanisamy CP, Cui B, Zhang H, Jayaraman S, Kodiveri MG. A comprehensive review on corn starch-based nanomaterials: properties, simulations, and applications. Polymers (Basel). 2020;12:2161.

31. Waterschoot J, Gomand SV, Fierens E, Delcour JA. Production, structure, physicochemical and functional properties of maize, cassava, wheat, potato and rice starches. Starch-Starke. 2015;67:14-29.

32. Shinagawa M, Hoshino W, Yamaguchi H, Yamada N, Suzuki E-I. Monitoring the hydrolysis and transglycosylation activity of a-glucosidase from Aspergillus niger by nuclear magnetic resonance spectroscopy and mass spectrometry. Anal Biochem. 2009;393:23-8.

33. Kato N, Suyama S, Shirokane M, Kato M, Kobayashi T, Tsukagoshi N. Novel alpha-glucosidase from Aspergillus nidulans with strong transglycosylation activity. Appl Environ Microbiol. 2002;68:1250-6.

34. Kumar S, Basu A, Anu-Appaiah KA, Gnanesh Kumar BS, Mutturi S. Identification and characterization of novel transglycosylating alpha-glucosidase from Aspergillus neoniger. J Appl Microbiol. 2020;129:1644-56.

35. Ichinose S, Tanaka M, Shintani T, Gomi K. Improved a-amylase production by Aspergillus oryzae after a double deletion of genes involved in carbon catabolite repression. Appl Microbiol Biot. 2014;98:335-43.

36. Norouzian D, Akbarzadeh A, Scharer JM, Moo YM. Fungal glucoamylases. Biotechnol Adv. 2006;24:80-5.

37. Williamson G, Belshaw NJ, Noel TR, Ring SG, Williamson MP. O-glycosylation and stability. Unfolding of glucoamylase induced by heat and guanidine hydrochloride. Eur J Biochem. 1992;207:661-70.

38. Williamson G, Belshaw NJ, Williamson MP. O-glycosylation in Aspergillus glucoamylase. Conformation and role in binding. Biochem J. 1992;282(Pt 2):423-8.

39. Wang J, Wu Y, Gong Y, Yu S, Liu G. Enhancing xylanase production in the thermophilic fungus Myceliophthora thermophila by homologous overexpression of Mtxyr1. J Ind Microbiol Biotechnol. 2015;42:1233-41.

40. Liu Q, Gao R, Li J, Lin L, Zhao J, Sun W, Tian C. Development of a genomeediting CRISPR/Cas9 system in thermophilic fungal Myceliophthora species and its application to hyper-cellulase production strain engineering. Biotechnol Biofuels. 2017;10:1

41. Livak KJ, Schmittgen TD. Analysis of relative gene expression data using real-time quantitative PCR and the 2(T)(-Delta Delta C) method. Methods. 2001;25:402-8.

42. Shevchenko A, Wilm M, Vorm O, Mann M. Mass spectrometric sequencing of proteins silver-stained polyacrylamide gels. Anal Chem. 1996;68:850-8.

43. Liu Q, Li J, Gao R, Li J, Ma G, Tian C. CLR-4, a novel conserved transcription factor for cellulase gene expression in ascomycete fungi. Mol Microbiol. 2019;111:373-94.

44. Tyanova S, Temu T, Cox J. The MaxQuant computational platform for mass spectrometry-based shotgun proteomics. Nat Protoc. 2016;11:2301-19.

45. Li F, Liu Q, Li X, Zhang C, Li J, Sun W, Liu D, Xiao D, Tian C. Construction of a new thermophilic fungus Myceliophthora thermophila platform for enzyme production using a versatile $2 \mathrm{~A}$ peptide strategy combined with efficient CRISPR-Cas9 system. Biotechnol Lett. 2020;42:1181-91.

\section{Publisher's Note}

Springer Nature remains neutral with regard to jurisdictional claims in published maps and institutional affiliations. 